\title{
Uso de nefelina como fonte alternativa de álcalis em porcelanatos: caracterização reológica e física
}

\section{(The use of nepheline as alternative source of alkalis in porcelain tiles: rheological and physical evaluation)}

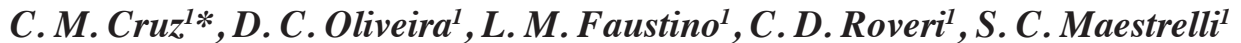 \\ ${ }^{1}$ Universidade Federal de Alfenas, Rod. José Aurélio Vilela 11999, 37715-400, Poços de Caldas, MG, Brasil
}

\begin{abstract}
Resumo
O porcelanato é um tipo de placa cerâmica de revestimento que vem se destacando atualmente por apresentar boas propriedades estéticas, como a superfície decorada, e mecânicas, como a baixa absorção de água e elevada resistência mecânica e ao ataque químico. As matérias-primas utilizadas para a produção de porcelanato são principalmente a argila e o feldspato. O feldspato é uma das matérias-primas responsáveis pela sinterização durante a queima e auxilia no desenvolvimento de baixa porosidade e elevada resistência ao desgaste da peça cerâmica. Porém, o Brasil apresenta reservas de feldspato em regiões distantes dos centros produtores, fato que encarece a produção deste produto. Dessa forma surge como alternativa a utilização de nefelina para substituir o feldspato, total ou parcialmente, pois este mineral apresenta características bastante similares. Para verificar a influência de tal substituição nas propriedades do porcelanato, inicialmente foi necessário realizar o estudo das propriedades reológicas e físicas da suspensão utilizada na produção. Os resultados encontrados mostraram que a viscosidade da suspensão tende a aumentar com a adição de nefelina, assim como a densidade aparente da peça após a queima.
\end{abstract}

Palavras-chave: porcelanato, feldspato, nefelina, viscosidade, densidade aparente.

\begin{abstract}
The porcelain is a type of ceramic tile which has been contrasted for its good aesthetical, such as decorated surface, and mechanical properties, such as low water absorption and high mechanical and chemical attack resistance. The raw materials used for porcelain tiles production are mainly clay and feldspar. Feldspar is one of the raw materials responsible for the sintering during firing and it helps on the development of low porosity and high wear resistance of the ceramic piece. However, Brazil presents feldspar sources in regions distant from production centers, leading to higher cost for the porcelain tiles production. Thus, nepheline is thought as an alternative to substitute feldspar, totally or partially, since this mineral presents very similar characteristics. In order to verify the influence of this substitution to the properties of the porcelain tiles, it was necessary initially to study the influence of nepheline addition in both rheological and physical properties of the suspension. The results showed that the viscosity of the suspension increases with the addition of nepheline, as well as the apparent density of the fired piece.
\end{abstract}

Keywords: porcelain tiles, feldspar, nepheline, viscosity, apparent density.

\section{INTRODUÇÃO}

A nefelina pertence ao grupo dos feldspatóides; é um mineral aluminossilicato de sódio, constituinte importante na formação de rochas com baixa quantidade de sílica, do grupo das rochas alcalinas, e apresenta propriedades que se assemelham às propriedades do feldspato. A maior parte das nefelinas apresenta composição química próxima de $\mathrm{Na}_{3} \mathrm{~K}\left(\mathrm{SiAlO}_{4}\right)$, que é considerada um composto de ordenação intermediária no sistema binário $\mathrm{NaAlSiO}_{4}-\mathrm{KAlSiO}_{4}[1]$.

*carolmoraescruz@gmail.com
Geralmente a obtenção de nefelina é feita a partir de nefelina sienito, que é uma rocha ígnea com grande quantidade de feldspatos sódicos e potássicos (álcalis), apresenta uma quantidade praticamente nula de quartzo livre e possui minerais ferromagnesianos [2]. Por apresentar propriedades semelhantes ao feldspato bem como possuir um elevado teor de alumina, a nefelina sienito é um substituto importante do feldspato na indústria cerâmica, pois a grande quantidade de álcalis presente gera a redução da fusibilidade e possibilita a sinterização das peças em temperaturas mais baixas. Contudo, a presença de óxidos de ferro, como a magnetita, é uma dificuldade encontrada na utilização da nefelina sienito, pois são os responsáveis por uma coloração indesejada para 
as peças de porcelanato. Assim, é preciso que os teores destes compostos sejam baixos e que seja feita a separação magnética [3].

O porcelanato é uma placa cerâmica de revestimento, que possui excelentes características técnicas [4], e recebe este nome por apresentar semelhanças nas características técnicas com relação à porcelana [5]. A crescente procura por esse material é devida às suas propriedades técnicas, como resistência mecânica, e estéticas, por poder apresentar uma superfície decorada conforme a aplicação desejada. O porcelanato é constituído de diferentes matérias-primas, sendo que a principal delas é o feldspato, responsável pelo estabelecimento das fases vítrea e líquida durante a queima, o que garante sua baixa porosidade e alta resistência ao desgaste, característica fundamental ao porcelanato. No entanto, o feldspato adequado à produção de porcelanato é encontrado principalmente no Nordeste (Paraíba e Rio Grande do Norte), resultando em alto preço devido ao frete. Como alternativa, tem-se a possibilidade de utilização da nefelina em substituição ao feldspato, devido às propriedades serem similares. Desta forma, torna-se interessante a análise das propriedades das massas cerâmicas de porcelanato substituindo total ou parcialmente o feldspato por nefelina, visando a manutenção da qualidade atual do produto.

\section{MATERIAIS E MÉTODOS}

Para as formulações analisadas, utilizaram-se como matérias-primas: quartzo, feldspato, nefelina, argila branca, calcita e zirconita. Tais matérias-primas são comumente utilizadas na formulação de porcelanatos e as mesmas já estavam beneficiadas, tendo sido fornecidas pela Mineração Curimbaba e Endeka Ceramics. A análise química das matérias-primas foi realizada pela técnica de fluorescência de raios X (FRX). A granulometria das matérias-primas foi determinada pelo ensaio de determinação de tamanho de partícula, usando o equipamento Malvern Mastersizer 2000.

Estudou-se o efeito da adição de nefelina em substituição ao feldspato, tendo sido elaboradas 5 formulações diferentes, fixando-se os percentuais dos outros componentes: $100 \%$ feldspato (formulação 1), $75 \%$ feldspato e $25 \%$ nefelina (formulação 2), 50\% feldspato e 50\% nefelina (formulação 3), $25 \%$ feldspato e $75 \%$ nefelina (formulação 4) e $100 \%$ nefelina (formulação 5). Os cálculos foram feitos com base

Tabela I - Formulações analisadas (\% em massa). [Table I - Sample formulations (wt\%).]

\begin{tabular}{cccccc}
\hline Matéria-prima & 1 & 2 & 3 & 4 & 5 \\
\hline Quartzo & 35,0 & 35,0 & 35,0 & 35,0 & 35,0 \\
Feldspato & 35,0 & 26,3 & 17,5 & 8,8 & 0,0 \\
Nefelina sienito & 0,0 & 8,8 & 17,5 & 26,3 & 35,0 \\
Argila & 25,0 & 25,0 & 25,0 & 25,0 & 25,0 \\
Calcita & 3,0 & 3,0 & 3,0 & 3,0 & 3,0 \\
Zirconita & 2,0 & 2,0 & 2,0 & 2,0 & 2,0 \\
\hline
\end{tabular}

em formulações encontradas em [6]; as formulações obtidas estão relacionadas na Tabela I.

Para a realização da caracterização reológica básica das suspensões estudadas foram realizados os ensaios de curva de consumo de defloculante ou curva de defloculação e ensaio de determinação da concentração crítica de sólidos ou curva de concentração de sólidos. O estudo da reologia foi necessário a fim de dar suporte à etapa de moagem e homogeneização da massa. O volume total estabelecido para as suspensões foi de $300 \mathrm{~mL}$; foram adotados como valores de massa específica real e massa específica aparente os valores de 2,65 e $1,70 \mathrm{~g} / \mathrm{cm}^{3}$, respectivamente (valores usuais para uma massa de porcelanato industrial) [7]. O volume de água adicionado na suspensão foi calculado como 201,5 mL, utilizando-se a Eq. A:

$$
\mathrm{V}_{\mathrm{H}_{2} 0}=\mathrm{V}_{\mathrm{s}}\left(\frac{\rho_{\mathrm{r}}-\rho_{\mathrm{a}}}{\rho_{\mathrm{r}}-1}\right)
$$

em que $\mathrm{V}_{\mathrm{H}_{2} 0}$ é o volume de água, $\mathrm{V}_{\mathrm{S}}$ é o volume de sólidos, $\varrho_{\mathrm{r}}$ é a massa específica real e $\varrho_{a}$ é a massa específica aparente. Foi utilizada água fornecida na rede de água do município de Poços de Caldas, uma vez que se almejaram condições esperadas no dia-a-dia fabril. Com os valores adotados, foi calculada a massa total de sólidos $\left(\mathrm{M}_{\text {seca }}\right)$ utilizada como 393,5 g para a composição da formulação, através da Eq. B:

$$
\mathrm{M}_{\mathrm{seca}}=\mathrm{V}_{\mathrm{s}} \cdot \rho_{\mathrm{r}}\left(\frac{\rho_{\mathrm{a}}-1}{\rho_{\mathrm{r}}-1}\right)
$$

A porcentagem real de sólidos (\%sol) contida nas suspensões foi calculada pela Eq. C, sendo obtido o valor de $66,13 \%$ :

$$
\% \text { sol }=\left(\frac{\mathrm{M}_{\text {seca }}}{\mathrm{M}_{\text {umida }}}\right) \cdot 100
$$

sendo,

$$
\mathrm{M}_{\text {úmida }}=\mathrm{V}_{\mathrm{s}} \cdot \rho_{\mathrm{a}}
$$

Os componentes da formulação foram pesados em uma balança analítica Digimed, DG-5000. Após a pesagem, os componentes receberam a quantidade previamente calculada de água para a obtenção da suspensão, além de 9 gotas $(0,46 \% \mathrm{~m} / \mathrm{m})$ de defloculante silicato de sódio (Merck-Sigma Aldrich), a fim de possibilitar a extração da suspensão do moinho, e seguiram para um moinho tipo periquito (moinho planetário, MA360/P), onde passaram por uma homogeneização pelo período de aproximadamente 10 min. Uma vez homogeneizada, a suspensão foi retirada do moinho e uma fração foi separada e acomodada em um béquer de $100 \mathrm{~mL}$, sendo levada a um viscosímetro rotacional Fungilab para a realização da primeira parte dos ensaios. Foi utilizado o spindle R6 do equipamento e o viscosímetro foi ajustado para $100 \mathrm{rpm}$, em medições de $2 \mathrm{~min}$. Foi realizada a medição da viscosidade inicial da suspensão analisada; em seguida, cada medição foi obtida adicionando-se uma gota 
do defloculante silicato de sódio à suspensão. As medidas foram realizadas até a estabilização dos valores obtidos pelo equipamento. O procedimento foi repetido duas vezes para cada formulação. Para a segunda parte da caracterização reológica, foi preparada uma suspensão contendo os mesmos valores em massa e água utilizados na primeira parte do experimento, sendo acrescentada a quantidade de defloculante silicato de sódio considerada ótima de acordo com a análise realizada no mesmo $(0,71 \% \mathrm{~m} / \mathrm{m})$. A suspensão foi levada ao viscosímetro, onde foi medida sua viscosidade inicial e, posteriormente, as viscosidades contendo um aumento na ordem de $3 \% \mathrm{~m} / \mathrm{m}$ por vez na porcentagem de sólidos, calculada segundo a Eq. C. O procedimento foi repetido até que a viscosidade da suspensão não pudesse mais ser medida pelo aparelho, sendo realizado para as cinco formulações analisadas e anotando-se todos os dados para as análises posteriores. O procedimento foi repetido duas vezes para cada formulação.

Em seguida, foram preparadas três formulações além das avaliadas nas curvas de defloculação, sendo F1 - 100\% feldspato, F2 - 100\% nefelina, e F3 - 100\% nefelina após separação magnética em separador magnético WHIMS (Wet High Intensity Magnetic Separator) da Inbras, com intensidade de campo magnético de até 13000 gauss. Os corpos de prova foram conformados em molde de metal de $7 \times 2 \times 0,8 \mathrm{~cm}$ (aproximadamente $20 \mathrm{~g}$ ), com umidade de $10 \%$ e pressão $250 \mathrm{kgf} / \mathrm{cm}^{2}$. A prensagem foi realizada em prensa hidráulica MPH-10, Marcon. Em seguida, eles foram secos a $110^{\circ} \mathrm{C}$ por $24 \mathrm{~h}$ em estufa (SL 102/221, Solab). A queima foi feita em mufla Jung (J200) em 1100, 1150 e 1180 ${ }^{\circ} \mathrm{C}$, com patamar de 120 min e taxa de aquecimento de 7 ${ }^{\circ} \mathrm{C} / \mathrm{min}$. Os corpos de prova após queima foram submetidos aos ensaios de densidade e porosidade aparente, absorção de água e retração linear de queima. A densidade aparente (DA), porosidade aparente (PA) e absorção de água (AA) foram medidas utilizando-se a técnica de imersão fundamentada no princípio de Arquimedes. A avaliação do produto após a prensagem é importante devido ao processo atual de produção de porcelanatos, através de prensagem e queima.

\section{RESULTADOS E DISCUSSÃO}

Materiais: a Tabela II mostra os resultados da análise química das matérias-primas utilizadas nesse estudo. A nefelina apresenta comumente um teor um pouco inferior de potássio, frente ao feldspato, porém mostra um teor mais elevado de sódio. Na somatória, o teor de fundentes (potássio e sódio) foi de aproximadamente $10 \%$ para o feldspato e $14 \%$ para a nefelina, o que pode resultar em menor temperatura de fusão para a nefelina, e menor viscosidade e melhor trabalhabilidade do porcelanato durante a queima. Ainda, a nefelina sienito apresentou alto teor de $\mathrm{Al}_{2} \mathrm{O}_{3}$ e menor teor de $\mathrm{SiO}_{2}$ que o feldspato, o que pode causar aumento na resistência ao risco e à quebra, além de melhorar a resistência ao ataque químico e choque térmico [8]. Na Fig. 1 encontram-se os gráficos obtidos de distribuição de tamanho de partícula para o feldspato e para a nefelina, uma vez que nestas matérias-primas concentram-se as principais diferenças observadas. Observou-se que a distribuição do tamanho de partícula para as duas matérias-primas foi bastante distinta, sendo que a nefelina apresentou tamanho médio de partículas (D50=13,98 $\mu \mathrm{m}$ ) menor que o feldspato (D50 = 16,54 $\mu \mathrm{m}$ ), além de uma tendência monomodal.

Curva de defloculação: as curvas obtidas estão relacionadas na Fig. 2. Pode-se observar que, considerandose os limites de confiança, todas as curvas apresentaram comportamento similar, principalmente considerando-se o ponto de defloculante ótimo. Tal fato é um bom indicativo da compatibilidade da nefelina em substituição parcial ou total ao feldspato. Apesar das curvas apresentarem-

Tabela II - Análise química das matérias-primas (\% em massa).

[Table II - Chemical analysis of raw materials (wt\%).]

\begin{tabular}{ccccccc}
\hline Componente & Quartzo & Feldspato & Nefelina & Argila & Calcita & Zirconita \\
\hline Perda ao fogo & 0,11 & 0,44 & 1,80 & 15,0 & 40,2 & 2,68 \\
$\mathrm{SiO}_{2}$ & 99,2 & 71,7 & 58,7 & 40,3 & 6,64 & 55,0 \\
$\mathrm{TiO}_{2}$ & 0,02 & 0,03 & 1,25 & 2,52 & - & 0,57 \\
$\mathrm{Fe}_{2} \mathrm{O}_{3}$ & 0,03 & 0,19 & 4,92 & 2,11 & 0,01 & 3,82 \\
$\mathrm{~K}_{2} \mathrm{O}$ & 0,03 & 8,36 & 13,9 & 0,83 & 0,01 & 8,24 \\
$\mathrm{Al}_{2} \mathrm{O}_{3}$ & 0,30 & 15,5 & 18,1 & 38,3 & 0,18 & 20,7 \\
$\mathrm{CaO}$ & 0,05 & 0,20 & 0,02 & 0,04 & 50,6 & 1,72 \\
$\mathrm{P}_{2} \mathrm{O}_{5}$ & 0,01 & 0,27 & 0,11 & 0,14 & 0,05 & 0,07 \\
$\mathrm{MnO}$ & - & - & 0,05 & 0,03 & - & 0,23 \\
$\mathrm{ZrO}_{2}$ & 0,05 & 0,04 & 0,24 & 0,29 & 0,01 & 0,15 \\
$\mathrm{MgO}$ & 0,03 & 0,06 & 0,01 & 0,27 & 2,23 & 0,33 \\
$\mathrm{Na}_{2} \mathrm{O}$ & - & 2,93 & 0,64 & 0,01 & 0,01 & 6,23 \\
$\mathrm{Cr}_{2} \mathrm{O}_{3}$ & - & - & 0,01 & - & - & 0,02 \\
\hline
\end{tabular}




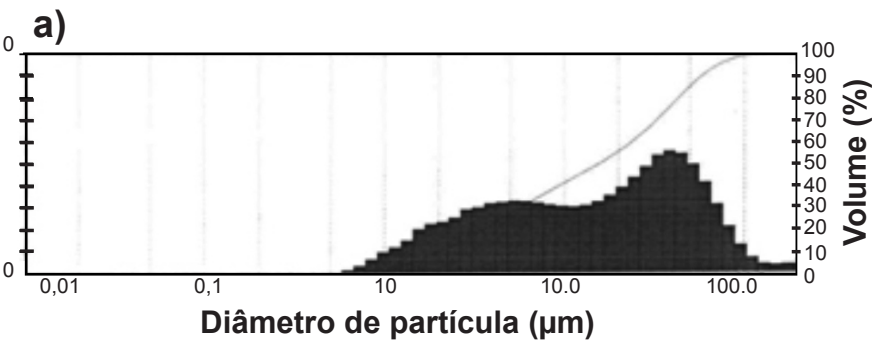

b)

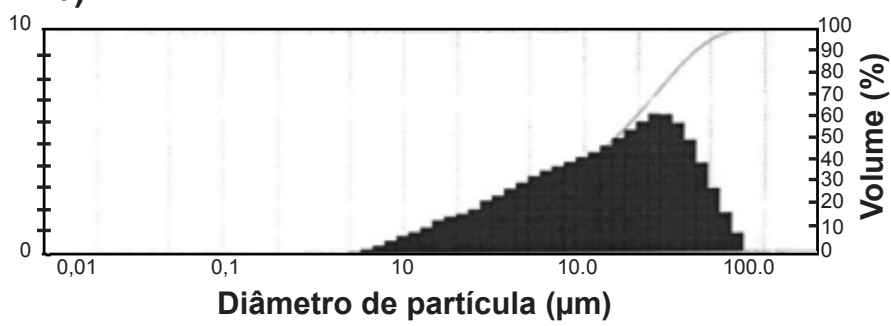

Figura 1: Distribuição de tamanho de partícula do feldspato (a) e nefelina (b).

[Figure 1: Particle size distribution of feldspar (a) and nepheline (b).]

se bastante semelhantes, observou-se uma tendência de diminuição da viscosidade das composições com maior teor de feldspato, o que pode estar relacionada à composição química (teor de sílica), como já apresentado. Foi possível observar que, para todas as formulações testadas, houve sedimentação da suspensão após $0,76 \% \mathrm{~m} / \mathrm{m}$ de adição de defloculante. Assim sendo, foi escolhido como ponto ótimo de defloculante o ponto com adição de $0,71 \% \mathrm{~m} / \mathrm{m}$ de silicato de sódio, pois ele oferece a menor viscosidade sem sedimentação. Foi possível observar também que, à medida em que a concentração de nefelina aumentou na suspensão, a sedimentação ocorreu de maneira mais abrupta e acentuada quando a adição de silicato de sódio foi igual ou superior a $0,76 \% \mathrm{~m} / \mathrm{m}$. É possível que, devido à alteração de pH (conforme indicado na Tabela III) causada pela adição de silicato de sódio, qualquer adição de defloculante poderia

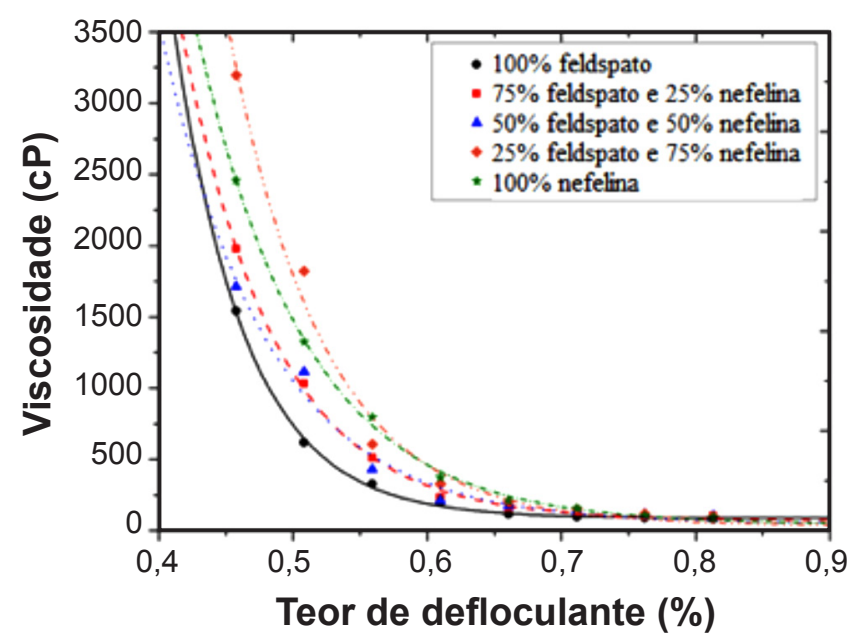

Figura 2: Curva de defloculação para todas as formulações. [Figure 2: Deflocculation curve for all formulations.]
Tabela III - pH das formulações antes e depois da sedimentação.

[Table III - $p H$ for formulations before and after sedimentation.]

\begin{tabular}{cccccc}
\hline $\begin{array}{c}\text { Defloculante } \\
(\% \mathrm{~m} / \mathrm{m})\end{array}$ & 1 & 2 & 3 & 4 & 5 \\
\hline 0,46 & 6,8 & 7,1 & 7,1 & 6,9 & 6,9 \\
0,76 & 9,4 & 8,7 & 8,6 & 9,0 & 9,0 \\
\hline
\end{tabular}

causar efeito contrário, ou seja, causar a floculação ou sedimentação da suspensão, já que o defloculante utilizado tem mecanismo de estabilização eletrostático [9]. Ainda, analisando-se os resultados de distribuição de tamanho de partícula, pode-se observar que a nefelina utilizada possuiu distribuição granulométrica monomodal. Tal fator pode ter contribuído para a maior sedimentação observada nas formulações com maiores teores de nefelina.

Curva de concentração de sólidos: as curvas obtidas são mostradas na Fig. 3. É notável que à medida em que a porcentagem de nefelina na formulação aumentou, houve o consequente aumento da viscosidade; contudo, mesmo diante de tal aumento, as formulações apresentaram o mesmo comportamento à adição de sólidos da formulação. Este aumento de viscosidade se deve ao fato de que a nefelina apresenta uma menor quantidade de sílica em sua composição química quando comparada ao feldspato e à maior presença de óxido de titânio e óxido de ferro, que dificultam a defloculação do sistema. Foi observado que, para as formulações com até 50\% feldspato e 50\% nefelina, o teor máximo de sólidos presentes foi de $84,13 \% \mathrm{~m} / \mathrm{m}$, enquanto que para maiores teores de nefelina esse teor caiu para $81,13 \% \mathrm{~m} / \mathrm{m}$. Outro ponto importante observado foi a coloração adquirida pela suspensão com a adição de nefelina. Nas formulações que envolveram feldspato, a suspensão apresentou coloração mais clara, e foi adquirindo tons mais escuros de marrom até que houve a substituição

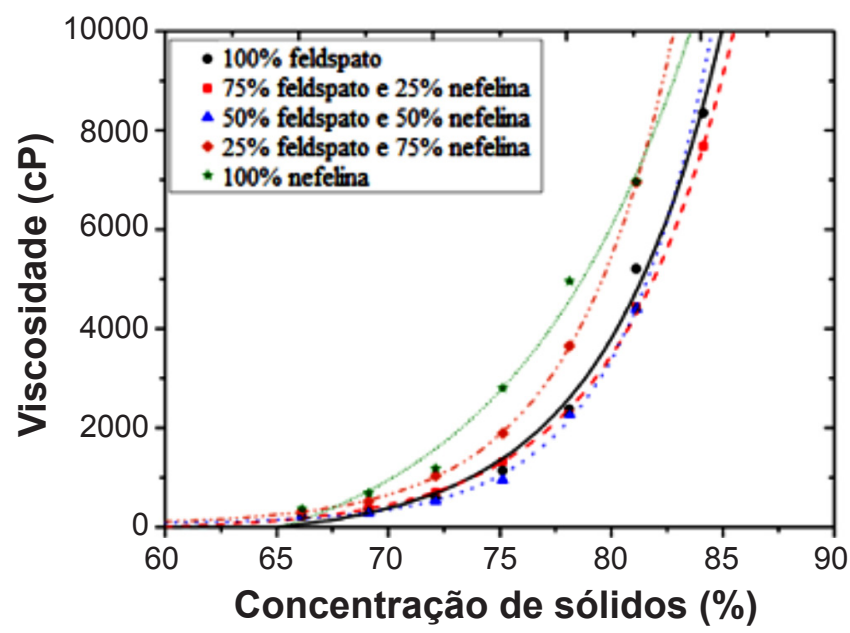

Figura 3: Curva de concentração de sólidos para todas as formulações.

[Figure 3: Solids concentration curve for all formulations.] 
total do feldspato pela nefelina. Este fato seria prejudicial à substituição desta matéria-prima, pois tradicionalmente as cerâmicas de revestimento são consideradas boas quando apresentam coloração branca; todavia, pode ser feita a separação magnética para atenuação deste fator. Ainda, atualmente o porcelanato é esmaltado, o que possibilita a utilização de massas com coloração mais escura.

Densidade aparente: foi observado que a coloração das peças com feldspato foi mais clara, e foi adquirindo tons mais escuros de marrom até que houve a substituição total do feldspato pela nefelina. Porém, quando realizada a separação magnética na nefelina, teve-se um clareamento na peça, conforme indicado na Fig. 4, sendo: F1 - 100\% feldspato, F2 - 100\% nefelina natural, e F3 - 100\% nefelina após separação magnética. Ainda, notou-se que as formulações contendo nefelina foram mais efetivas no desenvolvimento dos mecanismos de sinterização, conforme pôde ser concluído pelo aumento significativo da densidade aparente das peças (Fig. 5). Tal comportamento pode também ser justificado pela diferença de análise química entre a nefelina e o feldspato. A nefelina, por apresentar maior teor de álcalis e menor teor de sílica, além de não possuir quartzo livre, possui menor temperatura de fusão [8]. Dessa forma, observouse melhor sinterização dos corpos de prova com nefelina, comprovada pela maior densidade observada nesses corpos de prova, valor também exposto em [10]. As peças também apresentaram menor absorção de água quando foi adicionada nefelina na formulação [11]. Não foi observada diferença no

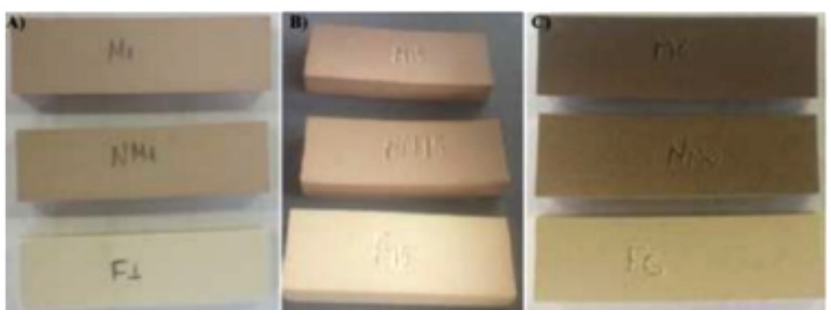

Figura 4: Corpos de prova F2, F3 e F1 (de cima para baixo) após queima a $1100{ }^{\circ} \mathrm{C}(\mathrm{A}), 1150{ }^{\circ} \mathrm{C}(\mathrm{B})$ e $1180{ }^{\circ} \mathrm{C}(\mathrm{C})$.

[Figure 4: Specimens $\mathrm{F} 2, \mathrm{~F} 3$ and $\mathrm{F} 1$ (top to bottom) after firing at $1100{ }^{\circ} \mathrm{C}(\mathrm{A}), 1150{ }^{\circ} \mathrm{C}(\mathrm{B})$, and $\left.1180^{\circ} \mathrm{C}(\mathrm{C}).\right]$

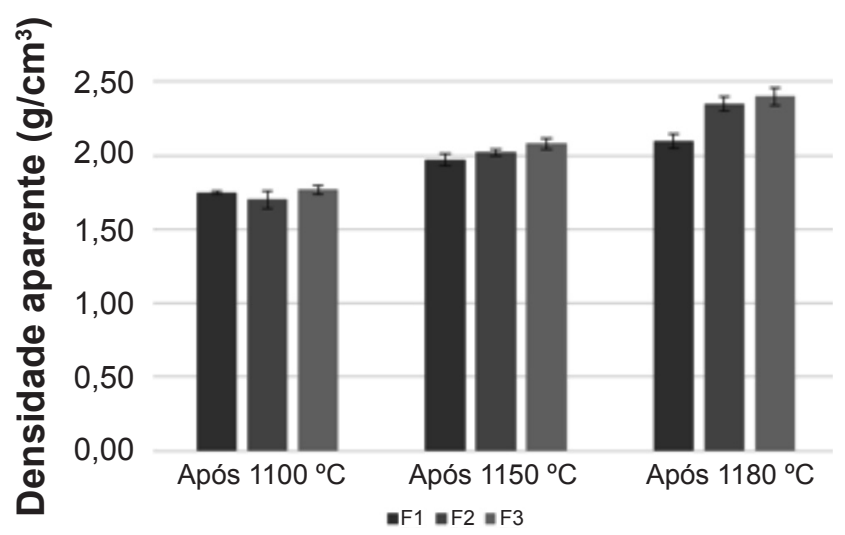

Figura 5: Densidade aparente dos corpos de prova queimados. [Figure 5: Apparent density of fired specimens.] valor de densidade das formulações com nefelina, com ou sem separação magnética. Os resultados encontrados foram similares aos observados em [12], podendo-se concluir que a nefelina não afeta negativamente as propriedades do porcelanato, podendo desta forma ser utilizada como substituinte do feldspato.

\section{CONCLUSÕES}

Com este estudo foi possível analisar as características reológicas da suspensão de porcelanato em 5 formulações distintas, desde o feldspato puro até a sua substituição total por nefelina. Foi observado que independentemente da quantidade de nefelina presente na suspensão o comportamento da curva de defloculação foi o mesmo, e todas tiveram um ponto ótimo de defloculante em $0,71 \%$. O comportamento semelhante também ocorreu para a curva de concentração de sólidos, contudo foi observado que à medida que a proporção de nefelina presente na suspensão aumentou, houve uma redução na quantidade máxima de sólidos que pode ser utilizada, reduzindo de $84,13 \%$ da formulação com maior quantidade de feldspato para $81,13 \%$ quando houve a mesma proporção entre os dois ou maior proporção de nefelina. Tais fatores podem ser explicados pela diferença de composição química da nefelina e feldspato. A nefelina apresentou teor de fundentes de aproximadamente $14 \%$, resultando em menor temperatura de fusão, menor viscosidade e melhor trabalhabilidade do porcelanato durante a queima. Ainda, a nefelina sienito apresentou alto teor de $\mathrm{Al}_{2} \mathrm{O}_{3}$ e menor teor de $\mathrm{SiO}_{2}$ que o feldspato, o que pode causar aumento na resistência ao risco e à quebra, além de melhorar a resistência ao ataque químico e choque térmico. A densidade das peças também tendeu a aumentar com a utilização de nefelina devido à melhor sinterização, e não foi observada influência da separação magnética na densidade das peças queimadas.

\section{AGRADECIMENTOS}

Os autores agradecem à Mineração Curimbaba e à Endeka Ceramics pelo fornecimento das matérias-primas utilizadas nesse estudo, e também pela realização dos ensaios de DRX, FRX e distribuição de tamanho de partículas das matérias-primas.

\section{REFERÊNCIAS}

[1] W.A. Deer, R.A. Howie, J. Zussman, Minerais constituintes das rochas: uma introdução, Fund. Calouste Gulbenkian, Lisboa, Portugal (2008).

[2] C.D. Roveri, L.H. Godoy, A.Zanardo, L.L. Silva, M.M.R . Moreno, F.C. Navarro, Rev. Inst. Geológ. 34, 2 (2013) 27.

[3] J.A. Sampaio, S.C.A. França, P.F.A. Braga, Rochas e minerais industriais: nefelina sienito, Cent. Tecnol. Min., $2^{\mathrm{a}}$ Ed, Rio de Janeiro, Brasil (2008).

[4] E. Sanchez, M.J. Orts, J. García-Tem, V. Cantavella, Cerâm. Ind. 6, 5 (2001) 15. 
[5] A.P.M. Menegazzo, "Estudo da correlação entre a microestrutura e as propriedades finais de revestimentos cerâmicos do tipo grês porcelanato", Tese Dr., Inst. Pesq. Energ. Nucl., S. Paulo (2001).

[6] J.A. Baucia Jr., L. Koshimizu, C. Gibertoni, M.R. Morelli, Cerâmica 56 (2010) 262.

[7] G. Biffi, O grês porcelanato: manual de fabricação e técnicas de emprego, Faenza Ed., S. Paulo, Brasil (2002).

[8] L. Esposito, A. Salem, A. Tucci, A. Gualtieri, S.H. Jazayeri, Ceram. Int. 31 (2005) 233.
[9] B.M. Cerrutti, "Estabilização de soluções aquosas de alumina pela adição de taninos e quitosana quartenizada”, Diss. Mestr., Un. S. Paulo, S. Carlos (2005).

[10] K.O. Teixeira, S.N. Monteiro, C.M.F. Vieira, Cerâmica 57 (2011) 32.

[11] C.M.F. Vieira, J.B. Soares, S.N. Monteiro, Cerâmica 54 (2008) 184.

[12] F.S. Hoffmann, G. dos Santos, M.R. Morelli, Cerâmica 58 (2012) 174.

(Rec. 23/04/2017, Rev. 23/07/2017, 30/08/2017, Ac. $12 / 10 / 2017)$ 